\section{Salir del Liceo como metáfora del Chile contemporáneo*}

\author{
Graduate from High School as a metaphor for \\ contemporary Chile
}

\author{
Claudio Duarte ${ }^{*}$ \\ MARIO SANDOVAL ${ }^{\star \star \star}$
}

\section{Resumen}

La movilización que las y los jóvenes estudiantes -secundarios y después universitarios- han venido desplegando en los últimos 10 años en el país (PNUD 2015) ha gatillado un conjunto de cuestionamientos a la estructura social y la desigualdad en ella contenida. Esto ha llevado a que diversos sectores -mundo político, opinión pública y otros- asuman esos planteamientos que organizan en buena medida la conversación social en Chile. Acceder a la educación superior

Artículo elaborado como resultado de la investigación del Proyecto Anillo JUVENTUDES financiado por CONICYT (SOC 1108). Agradecemos el análisis preliminar de los grupos de discusión, realizado por la Dra. (c) Jessica Jerez Yáñez, investigadora pasante del Proyecto.

** Universidad de Chile. claudioduarte@u.uchile.cl Casilla 125, Melipilla.

*** Universidad Católica Silva Henríquez. msandoval@ucsh.cl. es una sentida aspiración de las actuales generaciones de jóvenes que concluyen su enseñanza secundaria. Sin embargo, esta transición es experimentadacomoun conjunto de tensiones -desajuste, desacomodo y malestarque caracterizan el modo en que enfrentan y resuelven el paso de salir de cuarto medio. Dichas experiencias son una buena evidencia del tipo de sociedad chilena que se ha construido, y sus jóvenes, otra vez, una buena metáfora de la época actual.

Palabras clave: Juventud, Chile contemporáneo, egreso de enseñanza media, tensiones sociales.

\begin{abstract}
The mobilization of young students -from secondary schools and later from higher education- over the past 10 years in the country (PNUD 2015) triggered a series of challenges to the social structure and its inequalities. These demands have led actors from the political space and public opinion, among others, to take up these approaches that are organizing social conversation in Chile. The access to higher education is an aspiration for the young who are finishing their secondary education. However, this transition is experienced as a mix of tensions -imbalance, dislocation and uneasiness- which characterize the way they face and solve the transition to graduate from secondary education. Such experiences illustrate the kind of society Chilean people have built, the young, once more, being a good metaphor for the present time.
\end{abstract}

Key Words: Youth, contemporary Chile, high school graduation, social tensions. 


\section{Introducción}

Los modos de producirse como jóvenes en las sociedades contemporáneas son objeto de debate y análisis. Uno de los ejes de esas conversaciones sociales, refiere a las acciones que, desde diversas instituciones sociales, se espera lleven a cabo las y los jóvenes, en el marco de un momento de su vida que se define, desde paradigmas clásicos, como una etapa de formación y preparación para el futuro (Duarte 2012).

Visto así, el liceo y la familia de procedencia juegan un rol vital en este proceso, en las normatividades que en torno a él se construyen y en las formas en cómo resuelven las y los jóvenes las derivas que esta producción social implica. Se trata de jóvenes, que al alero de estas instituciones -y de otras, pero especificamos en ellas- buscan hacerse un camino, en medio de lo que, como veremos, se constituye como un rito de paso que marca cierres y aperturas, con un conjunto de tensiones que han de enfrentar.

Estas dinámicas se dan en un cierto contexto: el de un país que ha construido un sistema educacional que marca a fuego los modos de enfrentar y resolver estas exigencias producidas como rito en la salida de la enseñanza media (Bellei 2015). Estos modos de hacerse jóvenes, en unas ciertas condiciones estructurales, los observamos como una metáfora de dicha estructura (Benjamin, 2007). Vale decir, concebimos a las juventudes como una metáfora de la sociedad de su tiempo, en este caso a quienes están terminando cuarto medio como una metáfora de la sociedad chilena en su esfuerzo por organizar -ofrecer, imponer- los modos esperados de "inserción", "integración", "maduración" de sus jóvenes. Usamos comillas para destacar estos tres conceptos del conjunto de nociones construidas desde el paradigma clásico adultocéntrico, que construye unos imaginarios sobre juventud, como una etapa de tránsito y preparación para la adultez (Duarte 2012).

Terminar estudios y saber con claridad -definida desde las expectativas adultas- lo que se hará en el futuro, como preparación hacia esa adultez, es uno de los hitos claves en este proceso que marca el ciclo vital juvenil ${ }^{1}$.

Alejándonos de ese paradigma clásico señalado, concebimos más bien esta construcción social de juventud como un tiempo donde las capacidades de agencia y la valoración de lo producido en tiempo presente, juegan un rol fundamental en la elaboración de imaginarios de lo juvenil. Esa concepción nos permite dejar atrás las miradas estigmatizadoras -por riesgo, amenaza y carencia- de lo juvenil y nos permite abrir el análisis desde los posibles aportes y potencialidades que las y los sujetos jóvenes, en tiempo presente, pueden aportar en sus comunidades (Duarte 2016).

Durante el año 2014, realizamos 18 grupos de discusión en establecimientos secundarios del país, con estudiantes de cuarto año, de distinto nivel socio económico, provocando la conversación a partir de la interrogante: “¿cómo están viviendo su experiencia de salir de cuarto medio?". Nos interesó conocer la construcción de ideas/fuerza en las hablas juveniles, sobre sus valoraciones y aspiraciones en la situación de término de la enseñanza media, se trató de conversaciones en el ámbito de las lecturas

Para una crítica a este paradigma clásico adultocéntrico, ver Duarte 2001, 2012. 
ideológicas que hacen de esta experiencia (Canales 2006). La información producida fue analizada con la técnica de análisis de contenido (Andreu 2002; Navarro y Díaz 1994).

Esta información producida, nos permite, en una línea de análisis, dar cuenta de cómo la experiencia de salir de cuarto medio, para jóvenes chilenos/as se constituye en una metáfora de su país, a partir de las valoraciones que elaboran colectivamente. El análisis nos lleva a evidenciar las tensiones con que este proceso es experimentado y la forma en que ello hace alusión a su sociedad. Se trata del cierre de la conversación sobre una idea fuerza: después de terminar de estudiar la enseñanza media, lo que viene es más estudio, si se quiere obtener logros en esta sociedad. No se avizoran otras alternativas.

El sistema educativo chileno, ya no solo secundario, sino también terciario, parece haber logrado uno de sus propósitos expansivos: cautivar las aspiraciones juveniles y aparecer ante ellos y ellas como condición de camino único para el logro de la felicidad. Esto se complementa con que las expectativas que las personas adultas tienen de ellos/as, constituyen un refuerzo a esta acción cautivadora.

\section{La salida de cuarto medio tiene solo una vía.}

Diversos estudios evidencian que las características que ha desarrollado el sistema educativo en Chile, durante su expansión de los últimos 35 años, son un fiel producto del tipo de sociedad que se ha construido (Bellei 2015; Orellana 2012; OCDE 2009). La implantación de las transformaciones neoliberales de la dictadura y su posterior profundización en gobiernos civiles, ha permitido la consolidación, bajo su ideología, de la sentencia de que es a partir de la obtención de credenciales académicas que se puede optar a mejoras sustanciales en la calidad de vida (Orellana 2012). Esta última, en complementariedad entre la perspectiva de movilidad social que primó en buena parte del siglo XX (CEPAL/OIJ, 2008) con aquella que en la actualidad enfatiza que se trata principalmente de conseguir acceso a elementos de distinción vía consumo opulento (Pineda 2015; Duarte 2009; Moulian 1999).

El progresivo y exponencial aumento de la matrícula en educación superior durante las últimas décadas ${ }^{2}$, por la apertura de ofertas educativas universitarias y de formación técnico profesional superior, ha producido una modificación sustantiva en los modos de imaginar las posibilidades posteriores a la enseñanza secundaria. La educación superior aparece significada ya no solo como una posibilidad entre otras, como en décadas anteriores, sino que ahora es concebida como una vía necesaria, exclusiva y excluyente de otras para alcanzar logros en la vida. Tanto así, que seguir estudios superiores es imaginado como una continuidad obligada desde la educación media a la superior.

Las diferencias de clase social, por ejemplo, comienzan a producirse, cuando estos sujetos jóvenes precisan las características de este paso: las posibilidades de elección que tienen en educación superior -para los más ricos se trata de un amplio abanico, que incluye tipos de universidades y de carreras, incluso la

Entre 1990 y el 2007 la matrícula en educación superior en Chile aumentó en $176 \%$, con un total de 678.000 estudiantes, lo que representa 5,8 veces la matrícula de 1980 (OCDE 2009). 
posibilidad de otorgarse un tiempo de pruebas; mientras que para los sectores más pobres se trata de un alto esfuerzo que han de realizar para conseguir incorporarse, incluso puede estar mediado por experiencias laborales que permitan conseguir los recursos que posibiliten esa incorporación; en los sectores medios, es más diferenciado este proceso, dependiendo la elección de un algoritmo que incluye al menos cuestiones de esfuerzo y condiciones económicas de endeudamiento familiar- y los modos de resolver estas decisiones -para los sectores más ricos se trata de un proceso en que contarían con apoyo familiar aunque las diferencias de criterios sobre el tipo de carrera genera algunas tensiones, mientras que en los sectores empobrecidos se señala que existiría poco acompañamiento y mayor inestabilidad para sentirse seguros/as en las decisiones-. Para el conjunto de las y los jóvenes estudiantes, se trata de un momento de alta tensión, incertidumbre e incluso miedos por no querer fallar a quienes han puesto altas expectativas en su rendimiento, principalmente padres, madres y familias, y también sus profesores y profesoras.

Por ello se vive de manera tensionada -temores, agobio, cierta desesperación-, cuestión que suele leerse como propio del ser joven ${ }^{3}$, pero más bien lo concebimos como producto de un sistema de expectativas familiares que condiciona las formas de experimentar este proceso por parte de las y los jóvenes (Jelin 2010).

La salida a esa tensión, tiene diferencias de clase, desde quienes ven pocas posibilidades

A propósito de las ideas de crisis de identidad, moratoria y otras que han marcado al paradigma clásico adultocéntrico que define lo juvenil como problema social (Duarte, 2012). de elegir qué hacer -se ven obligados a solo estudiar- y quienes tienen seguridad de que seguirán estudiando y pueden otorgarse esa posibilidad de esperar un tiempo antes de continuar estudios, pero ello no está en discusión: estudiarán sin ninguna duda (Bellei 2015; Orellana 2012).

En las posibilidades de elección, un espejismo lo provoca la idea de que el mercado de la educación es democrático y la oferta está abierta y disponible para todos/as de igual manera. Sin embargo, las y los propios jóvenes se encargan de neutralizar esta noción, evidenciando que tanto la calidad de la formación que han conseguido, según su tipo de Liceo, y el costo de las instituciones en que les gustaría estudiar, constituyen dos condicionantes que ponen severos límites a las posibilidades de elección (Molina 2015).

Respecto de los modos de resolver estas tensiones, la asimilación -como adaptación funcional a lo que la estructura imponeaparece como la principal fórmula asumida por las y los jóvenes (Bourdieu 2000). No hay cuestionamientos radicales, sí abundantes quejas. Pero no se vislumbran alternativas, ni estrategias para enfrentar y superar estas condicionantes sistémicas. Ha de considerarse que estamos conversando con jóvenes que en su mayoría cursaba primero medio el año 2011 en que se desarrolló una fuerte movilización nacional por cambios en la educación superior -gratuidad, calidad y democracia institucional-, que tuvo amplia solidaridad y activación en las y los estudiantes de enseñanza media (Westendarp 2014).

Esta vía exclusiva -estudiar en la educación superior como continuidad inmediata o después 
de un descanso- y excluyente -casi no aparece la posibilidad del trabajo como alternativa-, se robustece y es característica singular de Chile en la región Latinoamericana (CEPAL/OIJ 2008). La alta tasa de retención en enseñanza media ${ }^{4}$ y la alta matrícula de educación superior (OCDE 2009), no son una tendencia en la región, más bien se enfatizan como logros de un sistema de educación de mercado que, a través de la privatización de la misma ${ }^{5}$, ha conseguido consolidar el imaginario prevaleciente de que la continuidad de estudios superiores es lo que corresponde a las y los jóvenes de la época presente. Incluso que la inserción al mercado laboral es una táctica que derivará en la gran estrategia que es seguir estudios superiores.

Así, estos procesos de salir de cuarto medio y continuar estudios, se experimentan desde un conjunto de tensiones sociales: desde el desajuste entre aspiraciones juveniles y expectativas adultas, desde el desacomodo con los propios deseos por parte de las y los jóvenes, y desde un cierto malestar con la estructura social que, según las voces juveniles, incentiva unos modos individualistas de llevar adelante esta tarea.

Al desajuste le llamamos tensión externa para graficar que se verifica desde actores adultos/ as que inciden en las opciones y experiencias juveniles; al desacomodo le llamamos tensión interna, para enfatizar que son las elaboraciones más propias de las y los jóvenes -teniendo en

Sobre el 95\% en Chile (MINEDUC, 2014).

El sistema educacional secundario en Chile se estructura en tres tipos de establecimientos, con distintas coberturas: la educación Municipal (de carácter gratuito) con solo el 37\%; la educación particular subvencionada (con co-pago 0 financiamiento compartido entre familias y el Estado) con 53\%; y la educación particular pagada (con cargo total a las familias) con $10 \%$ (MINEDUC, 2014). cuenta la alta imbricación entre ambas-; y al malestar, le conceptualizamos como tensión sistémica, en tanto da cuenta de cómo las estructuras e instituciones sociales influyen en las elaboraciones de estas tensiones. Sobre estas tres tensiones profundizamos a continuación.

\subsection{Tensión externa: las exigencias de la familia como desajuste.}

De manera transversal a los distintos sectores sociales de procedencia, las y los jóvenes caracterizan a sus familias como la principal instancia social que exige logros educativos. Ella es la que otorga las posibilidades de estudiar, pero al mismo tiempo, les marca el rumbo de lo que han de hacer, tanto en tiempo presente como en referencia al futuro que viene después de cuarto medio:

"Aquí estoy como por obligación pa' terminar el cuarto medio". Mujer, liceo municipal, Santiago.

El mecanismo no siempre es explícito, muchas veces se recurre a modos latentes, en que la significación sacrificial de lo que madres y padres "les han dado", de sus esfuerzos para que surjan, aparecen como la moneda de cambio que orienta sus decisiones hacia el futuro. Esto posee alta incidencia en los modos en cómo elaboran este hito de finalización de la enseñanza media.

\footnotetext{
“(...) eh mi mamá no me exige así como 'sabes qué tú tienes que estudiar y todo', pero hay un peso que más que nada así como de mi parte, que mi mamá ha hecho muchos esfuerzos por mí, educacionalmente hablando. Entonces yo creo que el hecho de que, por ejemplo, yo no estudie o no vaya hacia lo que me gusta hacer y saque una carrera, etc. Mi mamá se va a sentir decepcionada y para mí si yo llego a saber que mi mamá se sintió decepcionada
} 
y a mí se me parte el corazón, el alma y me parto yo, entro en 20 depresiones, porque eh no me, no me impone un peso tanto así como 'debes estudiar', pero tengo un peso sentimental con ella, porque yo la he visto partirse el lomo trabajando, durante toda su vida para mantener a mi hermano y a mí". Hombre, liceo municipal, Valparaíso.

"Pero es como una presión que involuntariamente te la dan, igual mi papá dice que no le haga caso, o sea aunque igual ella lo diga y yo no lo pesque, igual es una presión que uno tiende a sentir así como "no, no puedo ser menos que", "no puedo fallar" entonces... no sé igual estoy tranquilo en el sentido que me tiene que ir bien". Hombre, liceo particular pagado, Santiago.

En la búsqueda de no defraudar a sus familias, sus propios intereses y deseos como jóvenes -lo que comprendemos como sus aspiraciones (Bourdieu 1990)- son puestas en suspenso, como en un estado de latencia para postergarlas y cumplir con lo que serían las expectativas adultas. Una de las tensiones evidenciadas es en el desajuste entre las aspiraciones juveniles y las expectativas adultas, que como señala Bourdieu, corresponden con las luchas generacionales que en cada época se van actualizando. En el caso analizado, se refieren a la cuestión educacional como hito que marca las decisiones de presente y futuro.

\begin{abstract}
"Yo creo que igual va por un tema de a veces no hacerse uno mismo feliz, sino no decepcionar a su familia. Por ejemplo, mi papá siempre ha querido que yo elija una carrera en especial y siempre me dice 'yo sé que tú lo vas a hacer', 'yo sé que tú lo vas a hacer' y si no lo hago de repente voy a sentir como que más que fallarme a mí, le fallé a él. Igual es súper complicado porque están como en juego tus propias metas, tus propios gustos con los que al final esperan de ti y eso igual es una presión más no querer decepcionar a los que realmente esperan algo de ti". Mujer, liceo particular subvencionado, Puntas Arenas.
\end{abstract}

"Es que generalmente se basan en expectativas. Porque uno piensa: claro si yo quiero estudiar tal carrera, pero si no hay campo, si no tengo la ayuda económica, sino tengo una beca. Entonces uno estudia con esa visión, con una visión para tener algo seguro, o sea, como estudiar para seguir estudiando". Hombre, liceo municipal, Valparaíso.
En ese proceso, la familia no abre alternativas posibles: estudiar es construido e impuesto como un deber propio del ser joven de hoy.

\begin{abstract}
"Muchos están pensando en dar la PSU, lograr entrar a una carrera universitaria, así que lo que yo resumo es que la mayoría está haciendo lo que tiene que hacer y no necesariamente lo que le gustaría hacer". Hombre, liceo municipal, Valparaíso.

"Como que yo igual me siento presionada con el tema porque todavía no escojo una carrera y todos están esperando que escoja algo y también como que están esperando algo que no sé si yo pueda cumplirlo. Como que madure de un día para otro y sepa todo lo que voy a hacer de mi vida y yo todavía no lo he pensado". Mujer, liceo particular subvencionado, Puntas Arenas.
\end{abstract}

Por otro lado, en este contexto de educación de mercado, uno de los modos socializadores de la familia, respecto de la salida de cuarto medio, consiste en evidenciar el costo económico que tiene en Chile la continuidad de estudios superiores.

\footnotetext{
"Yo quiero estudiar Enfermería, igual no es tanto tema mi familia, tanto monetariamente. Porque mis padres me dicen, ya tú tienes que sacarte buenas notas por las becas $y$ todo, pero igual para mi es tema, porque pensando bien así en notas, igual me he puesto un poco flojo y yo cacho que monetariamente yo voy a tener que ayudar igual, no sé, trabajando en algo, aunque sea para pagar un poco, los primeros años que sea, porque igual $\mathrm{mi}$ hermano también quiere estudiar este año, porque todavía se está preparando y entrar a costear dos carreras igual es harto". Hombre, liceo particular subvencionado, Talca
}

Al momento de producir esta información las posibilidades de incorporar la gratuidad a la reforma educacional era parte del debate presidencial. Al momento de elaborar este artículo, se ubica como uno de los ejes de dicha reforma educacional que ya está prácticamente aprobada. Así, quizás en términos generacionales, estamos en presencia de uno de los últimos grupos que ha de tensionarse 
con esta situación del financiamiento de sus aspiraciones educativas. Mientras esto no se resuelva definitivamente, se mantiene en la conversación intra e intergeneracional como un asunto de relevancia, que condiciona las proyecciones y elaboraciones sobre la salida de cuarto medio.

Finalmente, la familia, ubicada en el contexto neoliberal que releva las credenciales académicas como vía para el éxito, marca a sus hijos e hijas con una exigencia que se mueve en la concreción del logro, como en el abstracto del símbolo que otorga prestigio.

\begin{abstract}
"Más que nada la presión de no desilusionar, porque hay todo un esquema, porque tus papás quieren algo para ti, quieren lo mejor para ti, supongo que todos los papás quieren eso. Entonces como que quieren que les vaya bien que sean exitosos, entonces eso ya te está restringiendo un área y uno ya está con la presión de, iino puedo desilusionar!! Tengo que hacer esto, tengo que hacer lo otro". Hombre, liceo particular pagado, Santiago.
\end{abstract}

Como se observa, las y los jóvenes establecen una relación directa entre los niveles de presión y miedo que declaran, respecto a las altas tensiones externas en relación a su futuro, especialmente de aquellas provenientes de sus padres y madres como referentes del grupo familiar: a mayor expectativa y exigencia externa, mayores son los planteamientos que observamos sobre angustia y temor al fracaso.

Estas expectativas y proyecciones adultas, toman un rol gravitante respecto de cómo los y las jóvenes estudiantes tematizan lo que están viviendo; declaran preocupación e inquietud respecto de la posibilidad de defraudar a quienes les han acompañado durante todo su desarrollo y quienes además se erigen como sujetos que más confianza les generan. Sin embargo, perciben que sus padres/madres buscan lograr su "auto realización" a través de sus hijos/as, lo que podría comprenderse como una instrumentalización en que los mundos adultos proyectan sus sueños truncados y les llevan a que intenten lograr lo que ellos/as no consiguieron. Cuestión que, de forma matizada, observamos de manera transversal en las distintas clases sociales y géneros.

Son estos adultos y adultas quienes también consolidan en sus jóvenes la visión hegemónica en el Chile neoliberal, de que los estudios universitarios y la consecuente obtención de un título profesional resultan claves para tener un futuro próspero y ausente de imprevistos. Esto se evidencia también por la minoritaria presencia de discursos que hablen de vocación, de anhelo por desarrollarse en áreas socialmente catalogadas como de bajo rendimiento económico (artes, humanidades, etc.).

En este contexto, aparece como la decisión más importante y casi como la única medida a tomar al terminar cuarto medio: el camino académico que seguirán. La elección de carrera universitaria y casa de estudios, constituyen la principal y casi exclusiva preocupación que se plantea en el horizonte.

En cuanto a esta asimilación de lo dominante (Bourdieu 2000) por parte de las y los jóvenes, llama la atención la lógica academicista y profesionalizante con la que operan. Prácticamente no hay lugar para otras formas de desarrollo en lo que viene, escasamente es nombrada la construcción de familia propia, no es visto como camino la adquisición de oficio ni tampoco la búsqueda del desarrollo espiritual o el camino religioso. En este sentido, no hay marcas de un discurso que menosprecie estas opciones de vida, sino más bien existe 
una completa invisibilización de cualquier otra opción de desarrollo personal que no sea la vía académica de educación superior.

Así, las exigencias familiares poseen tal potencia que se transforman en una tensión externa a las y los jóvenes, que aparecen como cumpliendo su cometido: el alineamiento en un camino al éxito por la vía de la obtención de credenciales académicas. En su discurso los y las jóvenes dejan claro que es una presión que tensiona, sin embargo no lo cuestionan mayormente y se someten a ellas. En ese sentido es que vemos una fuerte asimilación que resuelve este desajuste por la vía de la inhibición de la palabra juvenil y de unas aspiraciones que quedan subordinadas a las expectativas adultas.

En ese sentido, la forma de resolver esta exigencia es coherente con las expectativas que desde el modelo de educación de mercado se promueven en nuestro país (Bellei, 2015). Las experiencias juveniles al salir de cuarto medio son una buena metáfora del Chile contemporáneo.

\subsection{Tensión interna: el desacomodo como rito de paso}

El tiempo de salir de cuarto medio, está copado por el cronos. Hay un desenlace que tiene fecha y hora. Rendir la Prueba de Selección Universitaria $(\mathrm{PSU})^{6}$ y obtener una buena calificación se constituye en el hito específico que marcará un antes y un después en el año definido como de "grandes decisiones". En ese sentido, se constituyen como jóvenes que durante cuarto medio se siente jugando los

Prueba de Selección Universitaria (PSU), es un examen estandarizado a nivel país para quienes desean ingresar a la Educación Superior. descuentos de un juego de doce años, en que hay poco más que hacer y se percibe cada vez más cerca dicho hito.

Aparecen en los discursos juveniles un conjunto de sensaciones dominadas por las ansiedades, angustias e incluso desesperación. Ello se traduce en un profundo temor por fallar, por defraudar a otros/as y a sí mismo/a.

\footnotetext{
"Yentonces decidí pensar, en darme un tiempo después de salir del colegio para pensar lo que quiero hacer realmente y no en el momento, o sea, igual voy a dar la PSU porque mi mamá me obligó. También me pasa lo mismo, además que yo hago preu y como que el tiempo no me alcanza y también me pasaba lo mismo, yo en primero medio tenía listo lo que pretendía hacer. Pero ahora también no tengo ni segunda opción, siento que el puntaje quizá no va a alcanzar, no me veo preparada y la presión de todos que confíen en ti, pero si uno llega a fracasar va a estar eso, como mal... como van a decir eso de mí". Mujer, liceo particular subvencionado, San Fernando.
}

Plantean que las exigencias de tomar decisiones, por parte de sus familias y en el Liceo, al salir de cuarto medio, marcan el final de un momento que quisieran extender en el tiempo.

\footnotetext{
"Si, no alcanza a terminar la etapa de adolescencia y ya tiene que estar preocupándose de trabajo, de estudios" Mujer, liceo particular subvencionado, San Fernando.

'Se va a quedar atrás po'. Jaja. Na', son procesos que uno tiene que vivir. O sea, yo creo que todos en un momento saben que va a pasar. Como que es lo que uno no quiere que pase. Como que uno no se da cuenta de lo tan rápido que crece, como que no sé, como que me hubiese gustado ser chica más tiempo, como pa' valorar y apreciar todas esas cosas. Como que no me gustó haber crecido, son otras responsabilidades, como que son muchas preguntas, como que es una problemática súper grande e igual es como un peso súper grande que tiene que cargar cada persona". Mujer, liceo municipal Macul.
}

Sienten que les falta el tiempo. Les inquieta el tiempo diario, lo cotidiano, de las 24 horas del día, en que ya no logran realizar todas las 
actividades que quisieran; es tanto lo que les demanda el estudio y la preparación de la PSU que, o bien no pueden ocuparse de sus amigos/ as, el tiempo libre y la familia, o lo hacen de manera poco satisfactoria para ellos/as. Se va consolidando la sensación de estar en deuda, de estar postergando a quienes quieren.

\begin{abstract}
"Yo, yo, yo pienso que nosotros, por lo menos yo, estoy muy preocupada del futuro y de verdad no me estoy dando cuenta de que lo está pasando en mi presente. Por ejemplo ahora estoy con un stress, estoy viendo que voy al Preu, no voy al Preu, voy a esto, voy a esto otro, no me alcanza el tiempo y estoy solamente preocupada de la PSU. Es una cuestión de que a ti no te deja bien y no te dai' cuenta de lo que está pasando en tu familia, o sea dejai' a tu familia de lao', a tus amigos, a todos y después esa cuestión te pesa y uno no se da cuenta y creo que no soy la única que está así." Mujer, liceo municipal, Valparaíso.
\end{abstract}

\begin{abstract}
"Hablando de eso, hay como un término que se dice que uno es jedi cuando puede estudiar, en Cuarto, cuando podís' estudiar, cumplir en todo lo que es estudio, cumplir con tu familia, carretear y dormir, si podís' hacer esas cuatro cosas eris' un jedi. De verdad yo puedo cumplir tres de esas, yo puedo cumplir con la casa, yo puedo carretear y puedo dormir, pero con mi familia también la estoy dejando mucho de lado, entonces ahí yo estoy de acuerdo con él, no voy a dejar de carretear ni cagando." Hombre, liceo municipal, Valparaíso.
\end{abstract}

“Llegai' al Pre y tenís' que salir, después vai' llegai' a la casa, chato, muerto, tenís' que estudiar pa' la prueba del otro día y ahí claro, en cuánto tiempo tú te puedes dar el espacio para ti, sería esperar el fin de semana y estresarte toda una semana o bien darte un espacio que es como muy acotado y no sé po' relajarte. Yo me relajo, estirar las patas en el sillón y tal vez, no sé, fumarme un caño o un cigarro, pero ese es como mi relajo, pero es muy, muy difícil llegar a esas partes por lo menos en este tiempo, en estos momentos". Hombre, liceo municipal, Valparaíso.

Por otra parte, respecto del tiempo disponible hasta el día del hito PSU, es significado como una cuenta regresiva, que corre irrefrenable y que les obliga a encaminarse hacia la toma de decisiones con prontitud, ya que éstas son relevantes para su futuro.
"Entonces como que cada vez queda menos tiempo y tengo que decidir y ver dónde estudiar, que sea bueno, entonces como que el tiempo juega en contra". Hombre, liceo particular subvencionado, San Fernando.

Agudiza estas sensaciones que tensionan, lo que significan como falta de comprensión por parte de las personas adultas de sus familias y del Liceo. De ellos y ellas esperan mayor apoyo y empatía, lo que se ve obstaculizado por una suerte de urgencia adulta para hacerles cumplir lo esperado socialmente.

\footnotetext{
"O sea, a esta edad sobretodo. Como que la gente no se imagina, así como que creen que son problemas pasajeros, pero en realidad no, como que igual a uno le afectan mucho. Como que te da para pensar harto". Mujer, Liceo Municipal Macul

"Pero no sé si a esta edad realmente sé lo que voy a querer o lo que quiero, porque en esta edad todavía me encuentro en un proceso en el que quiero algo, después ya no lo quiero, después lo vuelvo a querer, entonces es como súper complicado". Mujer, liceo particular subvencionado, Puntas Arenas.
}

Es decir, vislumbran el acercamiento de un momento que viene cargado de decisiones, responsabilidades, tareas; eso genera en ellos mucha presión, angustia, miedo al fracaso, temor ante la posibilidad de defraudar a otros.

El tiempo les aparece corto, con un final que se acerca a pasos agigantados, las decisiones a tomar dependen de factores propios y ajenos. La sensación de que no se manejan todos esos factores y que lo que ocurra finalmente no depende sólo de ellos/as, aumenta la tensión interna que produce desacomodo.

A ratos quisieran volver atrás y refugiarse en una niñez carente de estas tensiones, en otros momentos sueñan con que todo ocurriera ya y sentirse liberados de la presión; entonces es buena cualquiera de estas posibilidades, con tal 
de salir de esta situación que perciben como de incertidumbre y con un final no claro.

De igual manera, incide en esta sensación, la idea socialmente construida de que en este momento, en estas decisiones, se juegan mucho de lo que será su vida futura: ahora se definen cuestiones que marcarán a fuego su desarrollo vital.

En una sociedad en que lo productivo y el acceso al consumo organizan buena parte de las relaciones sociales, vislumbrar el lugar que se ocupará en ello se vuelve relevante; en una sociedad como la chilena, en que tal como mostramos antes, ese lugar en lo productivo y el nivel de acceso a bienes está altamente condicionado por las credenciales educativas, las decisiones sobre qué estudiar al salir de cuarto medio son construidas como punto de inflexión en sus vidas.

Todo lo anterior aumenta el desacomodo como una tensión interna, con un tiempo-cronos que no cesa de avanzar y que no pueden controlar. Está ubicada en un plano íntimo-interior, que en dialéctica conexión con lo institucional -familiar y del Liceo-, se retroalimentan para recrearse como un asunto individual.

No hay comodidad, al contrario todo es incomodidad. Quizás en ese sentido se podría considerar un rito de paso, si por éste se comprenden las situaciones que tienen carácter público y que marcan el paso de una clase de edad a otra -son una situación liminar, de frontera-, que en algunas culturas están signados por ser hechos dolorosos en que cada individuo debe morir -a lo que deja- para volver a nacer -a lo que se abre- (Feixa 1998). Lo arriba presentado muestra que la salida de cuarto medio se constituye como un rito con características de proceso, como conjunto de situaciones acumulativas que conforman una experiencia social y que marcan a fuego las opciones que en ese momento asumen.

Se trata de un rito de paso como trayectoria, en que se producen las condiciones para obligar el paso de niñez a juventud y de juventud a adultez, haciendo del Liceo uno de los lugares modernos para que tal proceso se verifique. Por ello más que concebirlo como un hito posibilidad también importante por cierto- en que queda centrada la observación sobre el signo, planteamos la concepción de rito como proceso en que se expresa la conflictividad social y las tensiones en que estos cambios y transformaciones vitales acontecen.

Duele crecer, pero es un dolor socialmente provocado, a pesar de la naturalización con que estos jóvenes lo perciben, desde una mirada analítica les vemos, en coherencia con la tensión como desacomodo, reproduciendo las lógicas que en su contexto se imponen.

\subsection{Tensión sistémica: la búsqueda del éxito como deseo y malestar.}

A las tensiones que la familia les impone, a las tensiones construidas desde su forma para vivir este tiempo de decisiones, se suma una cuestión de orden sistémico. La sociedad en que se dan sus procesos vitales es una en que se promueve de manera relevante el éxito.

Ser alguien en la vida, está signado como la aspiración de todo individuo capaz y eficiente, integrado y adecuado a la norma. Así se establecen un conjunto de patrones en que su 
logro se mide a través de alcanzar posiciones de prestigio en la esfera productiva y reproductiva.

"A mí me dijeron, mis papás por lo menos me inculcaron desde chico: tienes que estudiar, ser exitoso, se te van a abrir muchas puertas, varias oportunidades, pero hay que tener cuidado con el tema de la envidia y todo eso, bueno ese es tema aparte. También me dijeron que tenía que hacer deporte, me inculcaron un millón de cosas al final, pero bueno me habían dicho eso y nunca me negaron el tema de lo que quería estudiar. Me dijeron que ser exitoso solamente en mi área y así me iba a ir bien en realidad, tener una vida estable y después hacer lo que yo quiera sin deber a nadie". Hombre, liceo particular pagado, Concepción.

"Igual decidir la Universidad donde estudiar es difícil porque uno ve la comodidad a nivel económico, el prestigio, si uno puede o no puede, entonces igual es difícil decidirse también... Yo creo que en realidad es lo que nos han dicho desde chicos, es algo que está como implantado desde que somos pequeños, si tú eres médico, si tú sigues una carrera, si tú eres el mejor del mundo, todo el mundo te va a envidiar, todo el mundo va a querer ser como tú, una cosa así. Entonces siempre te imponen el tema de que tienes que ser un profesional para ser alguien en la vida, siempre. Nunca te dicen: "sabes qué, lo importante -de repente lo dicen, pero no tan frecuentemente como lo otro- lo importante es ser feliz no necesariamente por los logros profesionales que uno tenga, sino por los logros personales". Hombre, liceo particular pagado, Concepción.

Las estrategias principales que se promueve utilizar son dos: por una parte, la que insiste en que el logro ha de ser en un ambiente de competencia, donde los mejores y fuertes son los que alcanzan las metas señaladas y los débiles son quienes fracasan; y en complemento, se enfatiza que este cumplimiento de metas es una tarea de orden individual que requiere de emprendimientos particulares.

En estas lógicas de competitividad e individualismo, se sostienen los mecanismos para ingresar a la Universidad: el puntaje PSU, el ranking del Liceo, las notas de enseñanza media $(\mathrm{NEM})^{7}$, les dejan en posición de tener que observar a sus semejantes del Liceo como rivales, posible competencia respecto de su cupo de ingreso a la educación superior y por tanto si no lo consideran se podrían frustrar en sus aspiraciones.

\footnotetext{
"Es que no quiero ser un tipo que habla de conspiraciones ni nada, pero estamos sumidos en un sistema que nos obliga en cierta parte a ser individualistas, a ser competitivos, de hecho el más claro ejemplo es la Prueba de Selección Universitaria". Hombre, liceo municipal, Valparaíso.
}

Este contexto, vinculado a las tensiones anteriores que ya analizamos, refuerza las sensaciones de temor y preocupación que manifiestan las y los jóvenes estudiantes.

\begin{abstract}
"Es más que nada la preocupación de lograr sacar un título, ser alguien, o sea, es como una preocupación de lograr las metas, cumplir esas metas y no quedar atrás, un stress". Hombre, liceo particular subvencionado, San Fernando.
\end{abstract}

Tal como señalamos antes, al momento de elaborar este artículo, se debate en Chile la implementación de una Reforma en la Educación Superior. En el contexto previo a la posibilidad de que se modifiquen las políticas de financiamiento de estudios, la tensión en las y los jóvenes aumenta, en tanto reconocen estar insertos en un contexto de educación de mercado.

Por ello, el esfuerzo al que se obliga a las familias a pagar la educación secundaria y en proyecciones, la educación superior, también fue planteado por los y las jóvenes como un elemento de tensión que está presente en sus decisiones.

Refiere al promedio de notas de los cuatro años de estudios secundarios, que otorgan un determinado puntaje para postular a estudios superiores. 
"La inversión económica, por todo los sacrificios que han hecho los demás por ti y lo que tú has hecho, por querer salir adelante y como dijo el Diego no ser alguien más del montón. Pero es difícil, es difícil pero hay que lograrlo, de alguna forma u otra". Mujer, liceo particular subvencionado, San Fernando.

Llama la atención que este panorama contextual que expresan, no es vinculado con los procesos sociales de reformas que hemos señalado. Se cuestiona el contexto en que están insertos, ya que perciben no estar viviendo el presente por estar preocupados/as del futuro, que las condiciones para tomar estas decisiones no son igualitarias, que la educación ha sido transformada en un bien de consumo; sin embargo, esto no logra tematizarse con una fuerza que permita la elaboración de reflexiones para unas acciones que pudieran encaminarse hacia acciones directas, por ejemplo de oposición y/o resistencia frente a este despliegue de expectativas y caminos que les son impuestos para la salida de cuarto medio.

Si nos proponemos, a partir del relato de los y las estudiantes, establecer un bosquejo de lo que es la sociedad chilena, partiendo de la premisa señalada, de que como jóvenes son una buena metáfora de la sociedad en que están viviendo, podríamos señalar que estamos frente a un modelo de sociedad altamente competitivo e individualista.

Desde esta lógica se invisibiliza cualquier otra forma de desarrollo personal que no esté vinculada con lógicas exitistas, que le permitan al sujeto ponerse por sobre otros/as, destacarse, "salir del montón". La comunidad desaparece, la familia desaparece, los vínculos desaparecen, tras la sombra de un sujeto individualista que solo persigue su éxito personal.
Situados desde una lógica consumista, se observa un modelo de sociedad donde no hay que desarrollar habilidades, donde no se crece, sino que solo se adquiere-compra aquello que se necesita o requiere para pasar a la siguiente etapa.

De esta forma, el malestar que expresan las y los jóvenes con esa sociedad, no es más que una "mirada al pasar", que no se detienen en sus raíces ni en sus consecuencias. Se trata de una elaboración de la sensación de vivir engañado (Mills 1959) que, reitera el modo epocal de producirse en sociedad. Es un modo que a pesar del malestar, acepta las condiciones de éxito que se le proponen y se encamina tras ello. Podríamos parafrasear la voz de uno de los jóvenes que con énfasis señaló que estaba dispuesto a ver "la parte media llena del vaso", en referencia al conjunto de oportunidades que la sociedad actual les ofrece, y no quedarse "en el lado medio vacío" que refiere a las desigualdades de condiciones para acceder a lo anterior.

Así, hacerse joven en la salida de cuarto medio, implica incluirse en los trayectos ya dibujados sistémicamente. En este proceso habrá procesos de debate y crítica juvenil, pero para que dicho trayecto sea de calidad y con más oportunidades, pero no para cuestionar, si se quiere, ontológicamente, su legitimidad social.

Estudiar es condición para hacerse joven -y luego adulto/a- en la sociedad chilena contemporánea, se trata de las generaciones de jóvenes que más acceso han tenido a educación. Pues bien, a pesar del malestar, quieren más educación y más credenciales educativas, porque ya asumieron que ahí están las claves del éxito en contexto neoliberal. 
Es relevante considerar que este hallazgo se posiciona de forma transversal en las distintas clases y géneros. Para los más ricos se trata de un trayecto ya andado por la generación anterior -padres, madres y hermanos/as mayores-, así es que no les genera dudas, sólo incertezas de la precisión de la decisión.

Para los sectores medios, se trata de una trayectoria que con esfuerzo individual y constancia podrán superar; la tensión se ubica en el tipo de institución de educación superior a elegir, en el resultado de la PSU y la búsqueda de una carrera rentable.

Para los sectores empobrecidos, aparece en su horizonte con mayor exigencia individual, pero como posibilidad -a diferencia de sus generaciones mayores- que depende de eso: de su esfuerzo y emprendimiento. Si no es al año siguiente de salir de cuarto, será al subsiguiente, incluso si han de trabajar un tiempo primero, será breve y como vía para reunir recursos que les permitan un ingreso posterior; pero estudiarán en la educación superior sí o sí.

\section{Consideraciones finales}

Salir de cuarto medio, terminar la enseñanza secundaria, se constituye en un paso que logra condensar de forma nítida la estructura social chilena, así como su ideología neoliberal.

Por una parte, muestra cómo se ha instalado con fuerza la noción de que el éxito en la vida, y los logros asociados, están condicionados por la obtención de las más altas credenciales académicas. Por otra parte, esa búsqueda de logros es asumida como una cuestión de orden individual y no de orden colectivo, por lo que se sostiene sobre una acción individual que implica esfuerzo y no considera en su despliegue la solidaridad ni la cuestión de derechos.

En ambos sentidos, las y los jóvenes constituyen hoy una generación que expresa a cabalidad lo que -desde el paradigma clásico- se espera les ocurra en el proceso de hacerse parte de la sociedad, como movimiento naturalizado y sistémico. Tal como hemos señalado, no consideramos el paso como un tránsito, como "estar de paso", sino como la condensación biográfica de estructura y capacidad de agencia, en que las y los jóvenes se desenvuelven intentando encontrar su camino y elaborar un trayecto que les otorgue logros.

En ese proceso, destacamos en el análisis presentado un conjunto de tensiones, que evidencian lo contradictorio del proceso descrito y los modos en que dichas biografías juveniles se ven cruzadas por unas ofertas que parecen abrir un conjunto de oportunidades, pero que al mismo tiempo se conflictúan en tanto las posibilidades reales están mediadas por relaciones e interacciones que condicionan esas posibilidades.

Así, cuestiones de orden sistémico -malestar-, asuntos de orden interno -desacomodo- y factores que refieren a las personas adultas de sus familias y Liceos -desajustes-, evidencian estas interacciones tensionadas por no coincidencia. Las aspiraciones juveniles tienen énfasis y pretensiones que no calzan con aquello que se les ofrece o impone.

Sinembargo, sus discursos muestranquelaqueja que desnuda estas tensiones está acompañada de argumentos que legitiman decisiones que llevan a adaptarse a estas posibilidades que el 
contexto ordena. La queja se va transformando en definiciones de cierto realismo que empujan a ubicarse dentro del camino trazado, aunque sea por otros. Así hay disposición a renunciar a lo deseado para incluirse en lo esperado por otras y otros. La condición estructural termina definiendo las disposiciones de agencia.

Estas consideraciones, podrían parecer a contracorriente de los procesos de activación juvenil estudiantil que se han dado en nuestro país en los últimos quince años ${ }^{8}$. Sin embargo, nos parece que son de alta coherencia, en tanto dichas movilizaciones han buscado que se mejore el acceso, se impida el lucro y haya calidad. No es una demanda por subvertir el orden del sistema educacional y lo que lo

Comenzando desde la movilización denominada "mochilazos" del año 2001 , en que se pedía la no privatización del pase escolar. educativo implica en sus vidas, sino que se mejoren las posibilidades de llevar a cabo lo esperado, que ya en estas generaciones de jóvenes comienza a transformarse en lo soñado.

También es de alta coherencia con la sociedad chilena, en el sentido de la metáfora planteada inicialmente, toda vez que se busca hacerse parte de la fiesta neoliberal, en especial en la variante de acceso al consumo que otorga prestigio y acceso a bienes. La obtención de credenciales educativas es condición para ese proceso.

Así, estudiar este paso y las trayectorias que se producen, nos ha permitido observar a la sociedad chilena en su eficacia ideológica, esto es, en su capacidad de ofrecer a las y los jóvenes puestos y caminos que hagan biografías sustentables, y que pretenden inhibir posibilidades de anomias o reflexión crítica.

\section{Bibliografía}

Andreu, J. 2002. Las técnicas de análisis de contenido: una revisión actualizada. Andalucía: Fundación Centro de Estudios Andaluces.

Bellei, C. 2015. El gran experimento. Mercado y privatización de la educación chilena. Santiago: Lom ediciones.

Benjamin, W. 2007. Obras. Libro II/ vol. 1. Abada: Madrid.

Bourdieu, P. 1990. "La juventud no es más que una palabra". Sociología y Cultura. México: Grijalbo

\section{Anagrama}

2000. La dominación masculina. Barcelona:

Canales, M. 2006. Metodología de Investigación Social. Introducción a los Oficios. Santiago de Chile: LOM Ediciones.

CEPAL/OIJ. 2008. Juventud y cohesión social en Iberoamérica. Un modelo para armar. Santiago de Chile: CEPAL-OIJ

Duarte, K. 2016. "Genealogía del Adultocentrismo. La constitución de un Patriarcado Adultocéntrico". Juventudes en Chile. Miradas de jóvenes de investigan. Duarte, C. y Álvarez, C. (Editores) Santiago de Chile: Social-Ediciones. Universidad de Chile. 2012. "Sociedades adultocéntricas: sobre sus orígenes y reproducción”. Revista Última Década 36: 99-125. 2009. "Sobre los que no son aunque sean. Éxito como exclusión de jóvenes empobrecidos en contextos capitalistas". Revista Última Década 30: 11-39

.2001. "¿Juventud o Juventudes? Versiones, trampas, pistas y ejes para acercarnos progresivamente a los mundos juveniles". Acerca de Jóvenes, Contraculturas y Sociedad Adultocéntrica. Duarte, K. Zambrano, D. San José de Costa Rica: DEI. 175-198.

Feixa, C. 1998. De jóvenes, bandas y tribus. Barcelona: Ariel. Jelin, E. 2010. Pan y afectos. La transformación de las familias. Buenos Aires: Fondo de Cultura Económica.

Mills, W. 1959. La Imaginación Sociológica. Nueva York: Fondo de Cultura Económica.

MINEDUC.2014. "Educaciónenunamirada. Informeestadístico del Centro de estudios del MINEDUC". Disponible en: http:// sgdce.mineduc.cl/descargar.php?id_doc $=201502111632580$. (Consultado marzo 2016).

Molina, W. 2015. "Juventudes y procesos de escolarización secundaria en el Chile contemporáneo". Juventudes. Metáforas del Chile Contemporáneo. Cottet, P. Santiago: RIL.

Moulian, T. 1999. El consumo me consume. Santiago de Chile: LOM Ediciones. 
Navarro, P. \& Díaz, C. 1994. "Análisis de Contenido". Métodos y técnicas de Investigación en Ciencias Sociales. Madrid: Editorial Síntesis.

OCDE. 2009. Panorama de la Educación. Indicadores de la OCDE 2009. Madrid: Santillana.

Orellana, V. 2012. "Sobre el malestar social con la educación y la energía del movimiento social: el primer paso del siglo XXI". Es la educación, estúpido. Varios autores, Santiago: Editorial Planeta.

Pineda, W. 2015. El consumo simbólico como práctica social y la reafirmación de rasgos identitarios como pertenencia a grupos de status, en jóvenes urbanos profesionales. Tesis para otra al grado de Magíster en Ciencias Sociales, mención Sociología, Universidad de Chile. Santiago.

PNUD. 2015. Desarrollo Humano en Chile. Los tiempos de la politización. Santiago: Programa de las Naciones Unidas para el Desarrollo (PNUD).

Westendarp, P. 2014. Juventudes en movimiento: construcción de vínculos comunitarios en tomas de liceos, en la movilización estudiantil chilena del 2011. Tesis para otra al grado de Magíster en Psicología Comunitaria, Universidad de Chile. Santiago. 
